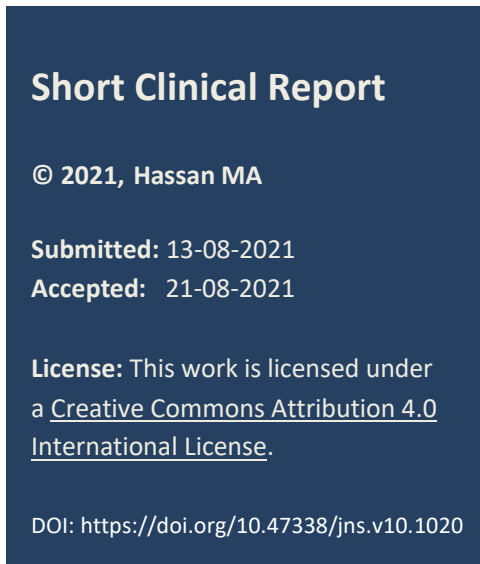

\title{
Type III wide colonic atresia: An etiological introspection
}

Moaied A Hassan*

Department of Pediatric Surgery, Basrah Children's Specialty Hospital, Basrah, Iraq.

Correspondence*: Moaied A. Hassan, Department of Pediatric Surgery, Basrah Children's Specialty Hospital, Basrah, Iraq. E-mail: moaied70@yahoo.com

\section{CASE PRESENTATION}

A full-term 2-day-old male baby, born to a 36-yearold multipara with uneventful antenatal and perinatal periods, presented with failure to pass meconium and bilious vomiting. On examination, the abdomen was hugely distended. Erect abdominal X-ray revealed dilated loops of bowel with multiple air-fluid levels. Rectal stimulation and irrigation were unyielding. Barium enema revealed hypoplastic microcolon with the arrest of the dye at the level of the sigmoid colon. After optimization and ruling out associated anomalies, explorative laparotomy was performed that showed ascending colon atresia, with a wide defect in the mesentery-type III colonic atresia (Fig. 1).

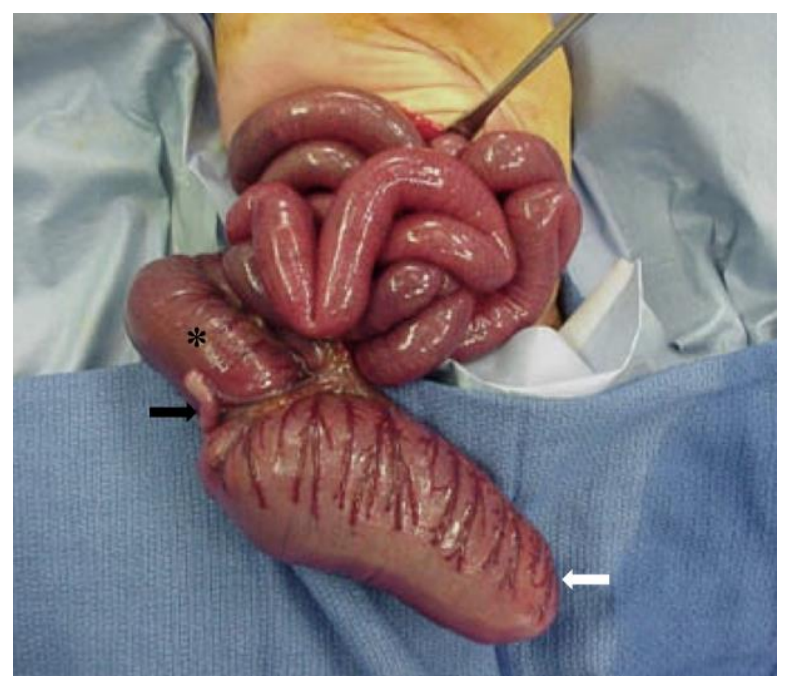

Figure 1: Atresia of the ascending colon in a two-day-old newborn. Atretic blind segment (white arrow), appendix

(black arrow), and terminal ileum (asterisk).

The distal atretic end was at the sigmoid colon. The proximal end was exteriorized as a colostomy, and the distal end as a mucous fistula. Distal colonic biopsies ruled out associated distal Hirschsprung's disease. The postoperative course remained uneventful. The baby is on our follow-up, with an intended program of frequent distal colonic irrigations with saline to stimulate bowel growth to minimize the discrepancy between proximal and distal segments in preparation for a colostomy reversal.

\section{DISCUSSION}

Colonic atresia is a rare cause of neonatal intestinal obstruction, with an incidence of $1: 66,000$ live births.[1] It is associated with multiple congenital anomalies including abdominal wall defects, malrotation, small bowel atresia, Meckel's diverticulum, and Hirschsprung's disease.[1,2] Colonic atresia occurs in descending order of frequency at the sigmoid, splenic flexure, hepatic flexure, and ascending colon, respectively.[3] Surgical management includes colostomy with delayed primary anastomosis or primary colonic anastomosis.[1,4] Regardless site of the atresia, some authors reported good results with colocolic anastomosis and covering ileostomy.[5] Others still adopt a staged approach of initial colostomy followed by delayed colonic anastomosis as the preferred choice.[2]

Tandler hypothesized solid cord theory of the development of atresia but seems pertinent to the development of duodenal atresia.[3] Louw and Bernard proposed mesenteric vascular accident as the etiology of atresia based on experiments on fetal puppies; their observation is widely accepted for most cases of jejunoileal and colonic atresias. Other possible etiologic factors include extrinsic mesenteric vascular obstruction associated with an internal hernia, volvulus, strangulation in tight gastroschisis, or intussusception.[2,3]

As the index case has wide atresia with complete loss of transverse colon; in absence of other associated anomalies especially closing abdominal wall defect and with normal fixation and rotation of otherwise normal small and large bowels, we support an intrauterine vascular insult to the middle colic branch of the superior mesenteric artery and left colic 
branch of the inferior mesenteric artery as a proposed etiology to the development of colonic atresia in our patient

Acknowledgements: None

Conflict of Interest: None declared

Source of Support: Nil

\section{REFERENCES}

1. El-Asmar KM, Abdel-Latif M, El-Kassaby AA, Soliman $\mathrm{MH}$, El-Behery MM. Colonic atresia: Association with other anomalies. J Neonatal Surg. 2016; 5:47.

2. Saha H, Ghosh D, Ghosh T, Burman S, Saha K. Demographic study and management of colonic atresia: Single-center experience with review of literature. J Indian Assoc Pediatr Surg. 2018; 23:20611.
Consent to Publication: Author(s) declared taking informed written consent for the publication of clinical photographs/material (if any used), from the legal guardian of the patient with an understanding that every effort will be made to conceal the identity of the patient, however it cannot be guaranteed.

Author Contributions: Author(s) declared to fulfil authorship criteria as devised by ICMJE and approved the final version.

3. Mansoor H, Kanwal N, Shaukat M. Atresia of the ascending colon: A rarity. APSP J Case Rep. 2010; 1:3.

4. Montenegro D, Aragón S, Valero J. Colonic atresia in a newborn. Case Rep. 2018; 4:69.

5. Mirza B, Iqbal S, Ijaz L. Colonic atresia and stenosis: our experience. J Neonatal Surg. 2012; 1:4. 